\title{
环境监测质量控制与质量管理概论
}

\author{
吴群 \\ 辽宁省大连生态环境监测中心
}

DOI:10.32629/eep.v3i1.612

[摘 要] 环境监测目的在于通过分析关于环境质量的各项评定指标,并且根据实际的监测指标来判断当下的环境污染情况及环境保护工作质 量。同时还可以通过环境监测来了解环境的各个阶段的实际情况,并将所获得准确信息和数据上报给环境保护部门。另外环境监测还可以为解 决环境污染问题提供重要的科学依据。因此为了保障环境监测质量, 本文阐述了环境监测质量控制与质量管理工作的必要性及其主要作用, 对环 境监测质量控制与质量管理的策略进行了探讨分析。

[关键词] 环境监测; 质量控制; 质量管理; 必要性; 作用; 策略

环境监测是指对环境中的各种物质含量进行测定, 通过科学计算获得 环境指标, 由此来判断环境的质量水平以及受污染程度, 提供给相关部门 作出决策, 制定正确的政策, 是环境保护工作得以开展的重要前提和科学 保证。因此为了发挥环境监测工作的功能作用, 以下就环境监测质量控制 与质量管理进行了探讨分析。

\section{1 环境监测质量控制与质量管理工作的必要性}

环境监测质量控制与质量管理工作就是为保证环境监测提供的一系 列数据信息能够精准有效而采取的质量管理方法, 并且应用于具体的实践 工作之中。随着我国社会的不断发展, 人们越来越意识到环保工作的重要 性, 而我们国家和政府也逐渐增大了对环境监测工作的重视程度。

党的十九大对生态文明建设和生态环境保护进行了系统总结和重 点部署, 紧扣新时代我国社会主要矛盾的变化, 必须强化生态环境保护, 提出污染防治攻坚战是作为决胜全面建成小康社会的三大攻坚战之一。 环境监测作为生态环境保护的关键环节, 更是需要全面参与到污染防治 攻坚战的各个战役中去, 准确的监测结果是前提, 监测数据的质量就成 为重中之重。因此, 在不断提高环境监测站的监测能力的同时, 切实认识 实行环境监测质量管理工作的现实意义, 也要不断增大对环境监测质量 管理工作重视程度。这种重视除了要体现在思想意识层面, 还要不断落 实于具体的实践操作过程中, 使得我国环境监测管理工作能够得到进一 步的发展和完善。

\section{2 环境监测质量控制与质量管理的主要作用}

2. 1 有效提升人们环境保护意识

环境保护的重要意义不止在于环境污染治理, 更重要的是保护人类健

了高科技就能提高业务水平了, 而是要充分利用科技发展自己。因此, 气象 业务部门内部要优化部门的结构, 重视自身水平的提高。之外, 气象业务部 门的所有成员都应该具备提高自身素质的意识, 不仅仅要熟悉自己气象行 业里的知识, 还要有熟练地运用计算机的能力, 这样才能将计算机软件与 气象业务完美地结合。

计算机技术日渐成为人类竞争与生存的必备技能, 各行各业的人都迫 切地要求学习计算机知识和掌握计算机的使用方法,特别是我们气象部门 需要掌握和应用计算机为气象现代化建设服务。计算机技术软件应用于气 象业务能从根本上提高了气象业务部门的工作效率和工作质量, 使其做到 及时, 准确, 快速地传递和接收气象信息, 更好地满足社会生产生活的需要, 同时, 也为气象业务实现现代化建设提供了技术支撑。

此外, 打造气象服务平台, 既能够充分满足用户的气象信息自主查 询需求, 也有助于深化气象服务部门服务管理模式变革。在以往的气象
康。例如食品安全问题, 受到社会各界的广泛重视, 尤其是农产品质量监测 以及农田的环境监测。通过环境监测, 有助于提高市民的环保意识, 进一步 促进环境保护工作发展。

2. 2 促进经济与环境协调发展

随着我国社会经济的逐渐提升, 人们愈加重视环境保护工作的质量, 应用现代环境科学理论与方法, 科学合理的开发自然资源, 并且对环境予 以保护, 防止环境质量恶化, 进一步促进环境与经济建设协调发展。

2.3 为制定环保标准提供依据

环境监测行业有特定的环境监测标准, 例如判断水源、空气是否受到 污染及污染程度, 必须把监测数据与相关标准限值进行比较。如果环境遭 到破坏, 也需要根据标准来明确污染等级, 由此可以看出标准对于环境监 测而言极为重要, 环境监测系统在环境监测过程中对不同部位与时间进行 多元化监测, 将信息进行比较分析, 才能够确保监测数据的准确性, 进一步 推动环境保护工作发展创新。

2. 4 促进了环保工作发展

环保工作的内容广, 涉及到的范围也较多, 例如水资源污染。大气污 染、土地污染等等, 所以导致环境保护部门的工作范围也涉及到了我国的 各个地区, 而这样大范围的工作形式也在一定程度上影响了环保工作的有 效性, 例如治理过的地方出现二次污染, 污染较严重的地区使用不科学的 突击治理等等, 使得部分环保工作出现治标不治本的情况。这种情况下, 环境质量就需要采取更加科学合理的措施去解决问题, 而环境监测质量控 制为环保保护工作提供了科学且有效的依据, 为环保工作提供了有效的帮 助。例如对环境治理区域中利用监测技术找到其污染源; 利用监测技术与

服务工作中, 气象部门工作意识淡薄, 而且气象服务模式过于保守, 无法 满足时代发展需求。对此, 基于计算机网络技术, 构建气象服务平台, 能 够促进气象部门与用户的互动交流, 加强气象服务的互动与共享。同时, 在互动过程中, 气象部门也能够客观审视自身存在的不足, 结合用户的 实际需求进行完善, 不断提升气象服务水平。不仅如此, 气象服务工作人 员也要加强责任意识, 完善计算机网络技术, 提升综合素质, 以期为公众 气象服务贡献力量。

[参考文献]

[1]杜钧,钱维宏. 天气预报的三次跃进[J].气象科技进展, 2014,4(6):13-26. [2]高杰.计算机软件技术在气象业务中的应用[J].科技资讯,2008,(3): 104 . [3]韦汉勇. 地面气象测报业务辅助软件开发与应用 [J].广东气 象,2009,31(04):56-58. 
互联网的融合采集我国各地的水源污染、空气污染以及土地污染的数据情 况, 并进行分析整理等等。

2.5防范突发性污染

影响环境的要素难以预测, 会出现各种各样的要素, 也会产生突发性 污染问题。当前我国工业生产水平持续提高, 但是突发性污染事故的频率 也逐步升高, 严重威胁生态环境, 例如在突发性污染阶段, 如果并未及时有 效的做好完全监测工作, 将会严重影响环境保护工作的开展, 所以必须找 到及时有效的环境治理方法, 才能够对治理方案产生合理性影响, 否则会 耽误最佳环境治理时期。由此可以看出环境监测对于环境污染与治理有着 极为重要的作用, 所以必须加强环境监测质量控制。

\section{3 环境监测质量控制与质量管理的策略分析}

\section{1建立环境监测预警系统}

环境监测事关经济可持续发展, 要从实际出发, 多种举措并举, 全面带 动环境监测质量管理工作。在改革发展环境监测质量管理体系中要进一步 明确环境监测各岗位上的职责, 加强质量监督和考核。要以严谨的态度投 入工作, 确保数据监测的真实性和可靠性。判断监测范围的环境危害是环 境监测的重要任务, 监测需要依据危害的大小作出判断。对危险信号的预 警是监测工作效率的重要体现。要健全和完善环境监测预警系统, 根据危 害等级做好预警等级分类。工作中要善于及时发现问题, 及时作出预测警 报, 为采取正确治理措施提供第一时间的依据。

\section{2 完善环境监测管理制度}

环境监测工作应该严格按照《环境监测管理办法》执行, 当按照数据 准确、代表性强、方法科学、传输及时的要求, 建设先进的环境监测体系, 为全面反映环境质量状况和变化途径, 及时跟踪污染源变化情况, 准确预 警各类环境突发事件等环境管理工作提供决策依据。各级环境监测部门应 该加强检查和抽测, 严肃处理监测过程中弄虚作假、谎报数据、修改数据 等失职读职行为。加强对环境监测工作的监督管理, 支持监测过程中的各 种技术创新行为。

3. 3合理运用相关技术
(1)物理化学技术应用。当前我国科学技术的发展创新,物理化学融合 性也逐步提高, 物理化学与环境监测技术有效融合, 可以对各类环境污染 问题进行有效监控, 例如运用动态膜压法, 对环境污染较重的水资源进行 监测, 可以探寻到水资源的污染数据, 为净化水源工作提供数据支持。

(2)生物技术应用。将环境监测技术与生物技术有效融合, 能够进一步 促进环境监测技术的发展。目前我国环境监测技术有两类使用率较高的生 物技术：大分子标记物监测技术与PCR技术。这两类生物技术能够精准全 面的判断出环境的破坏污染因素, 切实提高环境监测工作质量。

(3) 信息技术应用。将环境监测技术与信息技术有效融合, 能够提高环 境保护的信息技术发展水平, 例如plc技术与无线传感器网络技术。p $1 \mathrm{c}$ 属 于新兴工业控制装置采用了先进的通信技术与自动化技术、电子计算机技 术具有抗热、防尘、抗震等各类特性, 所以在环境监测机器装置的硬件上 安置这类装置能够有效抵抗户外作业时的冰雪与雨水天气。无线传感器网 络技术应用于环境监测的传感器节点上, 由传感器模块与无线通信模块、处 理器模块、能量供应模块构成。

\section{4 结束语}

综上所述, 环境保护是为了人类生存环境更加舒适美好, 当前环境监 测已经成为环境环保的关键一环, 因此必须意识到环境监测的重要作用, 并且需要采取环境监测应用的措施, 从而保障环境保护的有效性。

[参考文献]

[1]李琳.强化环境监测全过程质量管理全面提升环境监测水平 [J].化 工管理,2017(34):52.

[2]杨婧,王山.浅谈环境监测在环境保护中的作用及其发展趋势[J].绿 色环保建材,2017(12):32.

[3]吴薇.杨娜.环境监测在生态环境保护中的作用及发展措施[J].化工 管理,2019(25):52-53.

[4]宋勇.论环境监测全过程质量管理提升环境监测水平 [J].资源节约 与环保,2019(02):34. 